08

\title{
Трансформация структуры поверхности мрамора под влиянием ударной волны
}

\author{
() И.П. Щербаков, ${ }^{1}$ В.И. Веттегрень, ${ }^{1,}$ А.Я. Башкарев, ${ }^{2}$ В.Б. Кулик, ${ }^{1}$ Р.И. Мамалимов ${ }^{1}$ \\ ${ }^{1}$ Физико-технический институт им. А.Ф. Иофрфе РАН, \\ 194021 Санкт-Петербург, Россия \\ ${ }^{2}$ Санкт-Петербургский политехнический университет Петра Великого, \\ 195251 Санкт-Петербург, Россия \\ ฯ e-mail: Victor.Vettegren@mail.ioffe.ru \\ (Поступило в Редакцию15 мая 2017 г.)
}

Методами рамановской, инфракрасной и люминесцентной спектроскопии исследовали строение осколков, образовавшихся после разрушения мрамора под действием ударной волны. Обнаружено, что в поверхностном слое осколков толщиной $\sim 2 \mu \mathrm{m}$ кальцит I трансформировался в высокобарическую фазу — кальцит III. Одновременно концентрация примесных ионов $\mathrm{Mn}^{2+}, \mathrm{Eu}^{3+}$ и др. уменьшилась в $\sim 4$ раза.

DOI: $10.21883 /$ JTF.2018.01.45486.2332

\section{Введение}

К настоящему времени большие успехи достигнуты в области кинетики деформации диэлектриков под действием ударных волн [1,2]. Начато построение дислокационной модели разрушения при ударно-волновом нагружении [3,4]. Первые экспериментальные данные о механизме разрушения диэлектриков были получены [5-9] благодаря созданию установок, регистрирующих динамику люминесценции с наносекундным разрешением. Установлено, что под действием ударной волны от 50 до $80 \%$ объема образца распадается на положительно заряженные ионы и электроны. Оставшаяся часть представляет собой осколки с размерами от нескольких $\mu \mathrm{m}$ до нескольких $\mathrm{mm}$.

В работах $[10,11]$ методами инфракрасной (ИК), рамановской и фотолюминесцентной (ФЛ) спектроскопии исследована поверхность осколков монокристалла кварца и гранитов до и после воздействия ударной волны. Обнаружено, что под влиянием ударной волны на их поверхности образовался слой из диаплектического стекла, вещества с чрезвычайно сильно искаженной кристаллической решеткой.

Настоящая работа продолжает цикл этих исследований. В ней было исследовано строение поверхности мрамора, образовавшейся после воздействия ударной волны.

Природный мрамор содержит кристаллы кальцита $\mathrm{CaCO}_{3}$, диопсида - $\mathrm{CaMg}\left(\mathrm{Si}_{2} \mathrm{O}_{6}\right)$ и волластонита $\mathrm{Ca}_{3}\left(\mathrm{Si}_{3} \mathrm{O}_{9}\right)$. Известно, что $\mathrm{CaCO}_{3}$ существует по крайней мере в трех фазах: при нормальном давлении $\mathrm{CaCO}_{3} \mathrm{I}$, выше $1.9 \mathrm{GPa}-\mathrm{CaCO}_{3}$ II и при давлении больше $2.5 \mathrm{GPa}$ начинается новый фазовый переход в $\mathrm{CaCO}_{3}$ III [12-14]. Величина давления в ударной волне достигает нескольких десятков $\mathrm{GPa}$. Поэтому можно было ожидать, что в поверхностном слое мрамора, наряду с диаплектическим стеклом может образоваться и $\mathrm{CaCO}_{3}$ III.

\section{Объект и методы исследования}

Для исследований был выбран образец мрамора в виде круглой пластинки диаметром $30 \mathrm{~mm}$ и толщиной $8 \mathrm{~mm}$. С одной стороны пластинки пропилен паз глубиной и шириной $\sim 3 \mathrm{~mm}$. В нем располагались медные электроды, расстояние между которыми $\sim 3 \mathrm{~mm}$. Они соединены с конденсатором, при разряде которого в промежутке между двумя медными проводниками образуется плазма, состоящая из микрочастиц и атомов $\mathrm{Cu}$ [15]. Она вызывает появление в $\mathrm{CaCO}_{3}$ ударной волны. Под ее воздействием от 60 до $70 \%$ образца распадается на положительно заряженные ионы, которые вылетали из образца в виде струи плазмы [9]. Остальная часть представляет собой осколки с размерами от нескольких $\mu \mathrm{m}$ до нескольких $\mathrm{mm}$. Для исследования изменения строения мрамора после воздействия ударной волны были выбраны несколько осколков, которые имели вид пластинок с поперечными размерами от 5 до $7 \mathrm{~mm}$, толщиной $\sim 3 \mathrm{~mm}$.

Для исследования строения осколков применяли 3 метода: рамановскую, ИК и ФЛ спектроскопию.

Для получения рамановских спектров пластинки устанавливали на предметный столик спектрометра Ramalog 5. Спектры возбуждали аргоновым лазером $\mathrm{Ar}^{2+} 16508$ (Spectra Physics), линия $488 \mathrm{~nm}$. Спектры записывали в режиме счета фотонов под углом рассеяния $\approx 180^{\circ}$. Спектральная ширина щели $-2 \mathrm{~cm}^{-1}$.

Спектры отражения неполяризованного ИК света записаны на фурье-спектрометре ИК-21 „Prestige“. Пластинки устанавливали на предметный столик приставки SRM-8000A. Угол падения луча ИК излучения на образец составлял $10^{\circ}$. Полученные спектры пересчитывали в спектры затухания (мнимой части диэлектрической функции) $\varepsilon^{\prime \prime}(v)$, где $v$ - частота. С этой целью использовали метод, предложенный в [16].

При отражении от поглощающего объекта амплитуда колебаний электрического вектора ИК-излучения зату- 


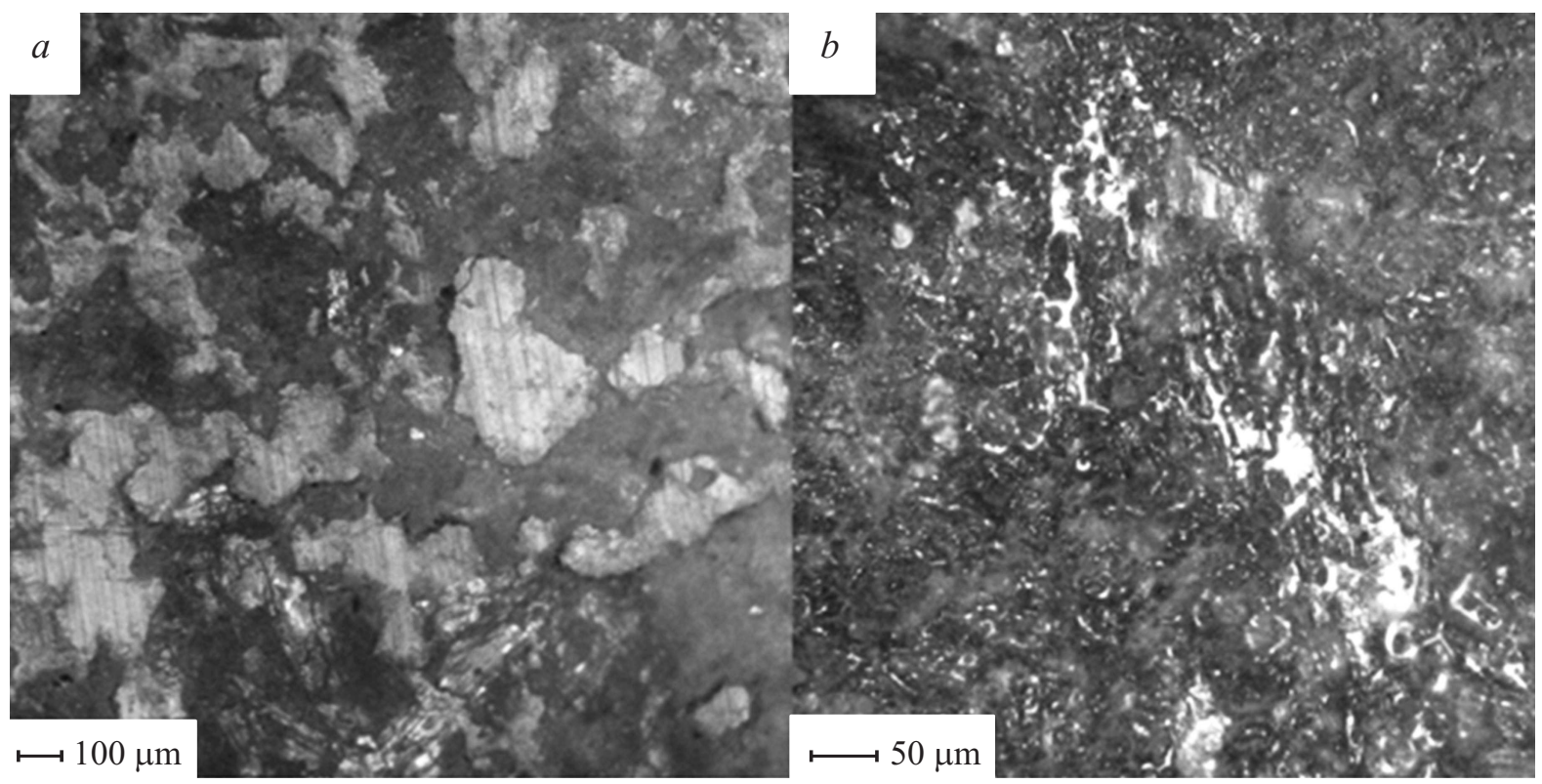

Рис. 1. Фотографии поверхности мрамора до $(a)$ и после $(b)$ воздействия ударной волны.

хает экспоненциально от поверхности вглубь образца. Глубина $h$, на которой она уменьшается в $e \approx 2.7$ раз (e - основание натуральных логарифмов), а интенсивность излучения - в $e^{2} \approx 8$ раз, соответствует эффективной толщине поверхностного слоя, о которой несет информацию спектр отражения. Ее вычисляли по формуле [17]:

$$
h \approx 1 / 4 \pi v k,
$$

где $k-$ показатель поглощения.

ФЛ возбуждали светодиодом UVTOP280TO39HS, длина волны излучения которого - $285 \mathrm{~nm}$. Спектры ФЛ регистрировали под углом $10^{\circ}$ к направлению луча светодиода оптоволоконным спектрометром - AvaSpecULSi2048L-USB2. Измеренную интенсивность полос нормировали на интенсивность луча лазера, отраженного от поверхности. Эффективная толщина поверхностного слоя на длине волны фотодиода составила $\sim 100 \mu \mathrm{m}$.

\section{Структура поверхности исследованного образца}

На рис. 1 показаны фотографии поверхности исследованного образца. До воздействия ударной волны на ней наблюдались зерна $\mathrm{CaCO}_{3}$, средний размер которых $\sim 40 \mu \mathrm{m}$ (рис. 1,a). После воздействия волны размер зерен уменьшился, по крайней мере, до нескольких $\mu \mathrm{m}$ (рис. 2,b).

\section{Данные рамановской спектроскопии}

Мрамор прозрачен для луча лазера с длиной волны $488 \mathrm{~nm}$, и анализ рамановских спектров (рис. 2) позво- ляет получить информацию о строении объема образца. Полосы 156, 283, 712 и $1087 \mathrm{~cm}^{-1}$ соответствуют колебаниям решетки $\mathrm{CaCO}_{3} \mathrm{I}[18], 327,358,393,665$ и $1014 \mathrm{~cm}^{-1}$ - диопсида $\mathrm{CaMg}\left(\mathrm{Si}_{2} \mathrm{O}_{6}\right)$ и $338,414,636$, 970 и $1044 \mathrm{~cm}^{-1}$ - волластонита $\mathrm{Ca}_{3}\left(\mathrm{Si}_{3} \mathrm{O}_{9}\right)$ [19,20].

Из рассмотрения рис. 2 следует, что интенсивность всех полос после воздействия взрывной волны заметно не изменилась. Это показывает, что концентрация этих минералов, усредненная по толщине образца $-3 \mathrm{~mm}$, после воздействия ударной волны осталась неизменной.

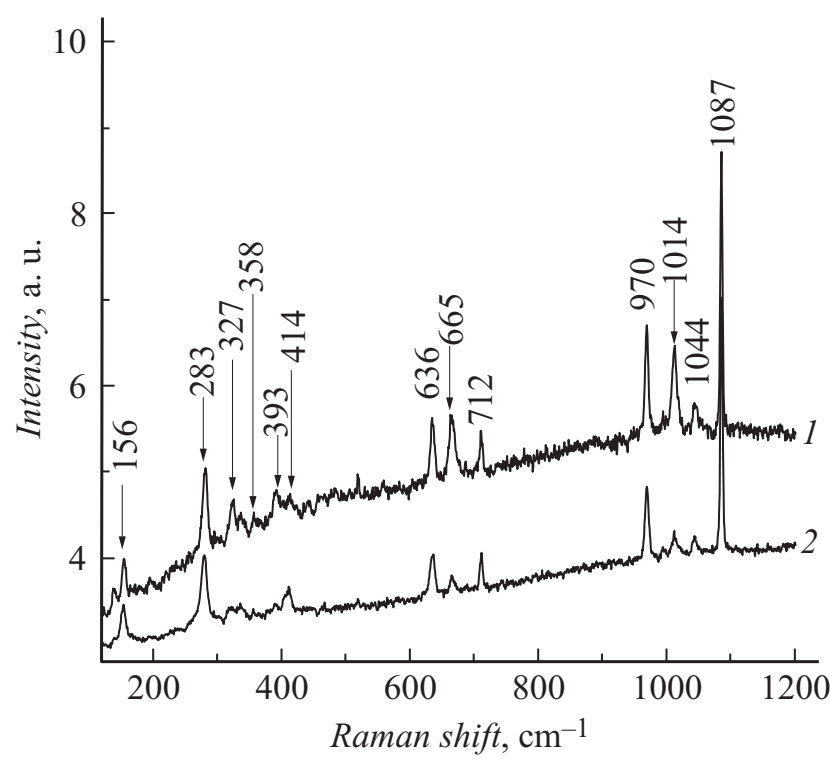

Рис. 2. Рамановский спектр мрамора до (1) и после (2) воздействия ударной волны. 


\section{Данные ИК спектроскопии}

На рис. 3 показан ИК спектр отражения в диапазоне от 1180 до $1670 \mathrm{~cm}^{-1}$, а на рис. 4 - рассчитанный

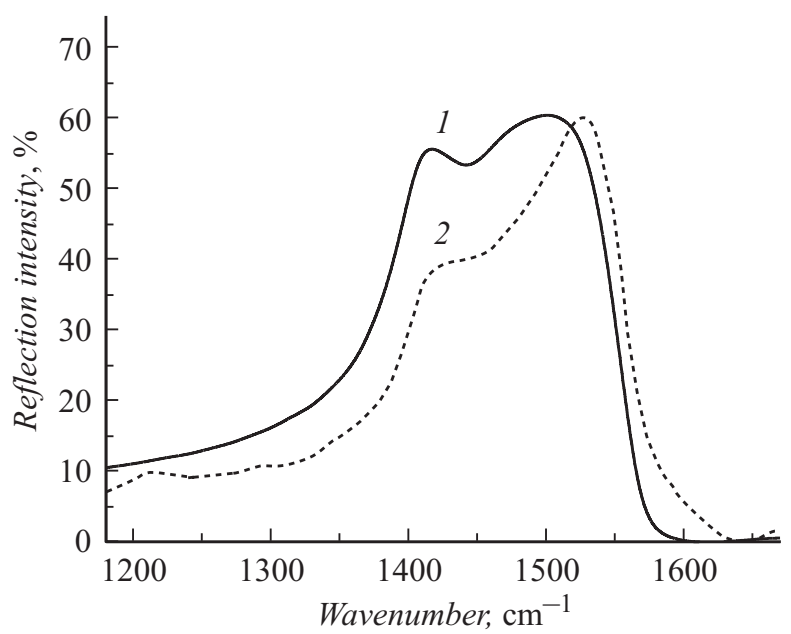

Pис. 3. Спектр отражения ИК излучения мрамора до (1) и после (2) воздействия ударной волны.
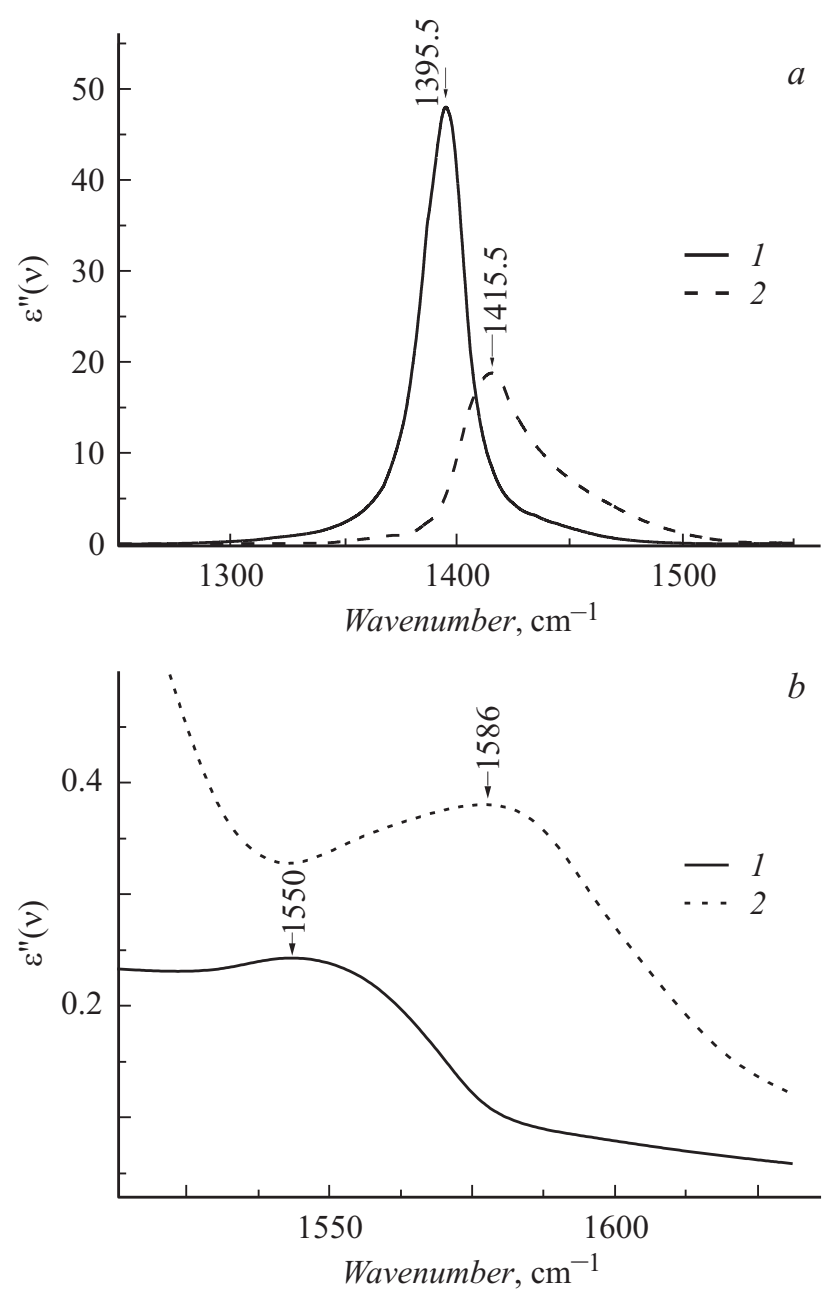

Pис. 4. Спектр затухания ИК излучения мрамора до (1) и после (2) воздействия ударной волны в областях $1250-1530 \mathrm{~cm}^{-1}(a)$ и $1425-1670 \mathrm{~cm}^{-1}(b)$.

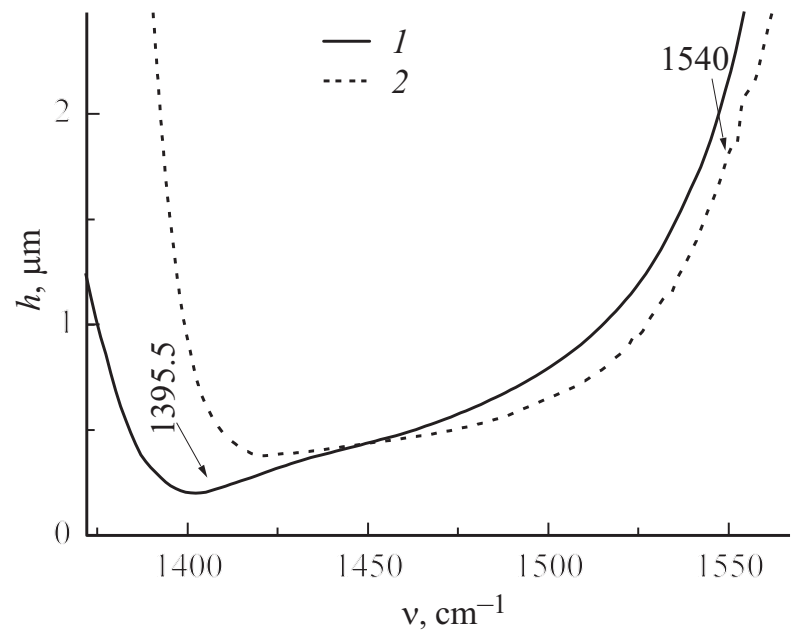

Рис. 5. Эффективная толщина поверхностного слоя $\mathrm{CaCO}_{3}$ до (1) и после (2) воздействия ударной волны. Стрелками показаны положения максимумов полос 1355.5 и $1540 \mathrm{~cm}^{-1}$.

из него спектр затухания $\varepsilon^{\prime \prime}(v)$. Эффективная толщина поверхностного слоя $h$ лежит в пределах от 0.1 до $2 \mu \mathrm{m}$ (рис. 5).

В спектре затухания $\varepsilon^{\prime \prime}(v)$ ИК излучения до воздействия ударной волны наблюдаются два максимума 1395.5 и $1550 \mathrm{~cm}^{-1}$. Первая $\left(1395.5 \mathrm{~cm}^{-1}\right)$ соответствует поперечным, а вторая $\left(1550 \mathrm{~cm}^{-1}\right)$ - продольным колебаниям кристаллической решетки кальцита [21-24].

Полоса $1395.5 \mathrm{~cm}^{-1}$ имеет симметричную дисперсионную форму (рис. 4). А именно зависимость затухания $\varepsilon^{\prime \prime}(v)$ от частоты $v$ описывается выражением

$$
\varepsilon^{\prime \prime}(v)=\frac{\varepsilon_{0}^{\prime \prime}\left(\frac{\Gamma}{2}\right)^{2}}{\left(v_{0}-v\right)^{2}+\left(\frac{\Gamma}{2}\right)^{2}},
$$

где $\varepsilon_{0}^{\prime \prime}(v)$ - мнимая часть диэлектрической проницаемости в максимуме полосы - на частоте $v_{0}$, а $\Gamma$ ее ширина (на половине $\varepsilon_{0}^{\prime \prime}$ ). Такая форма типична для полос идеально построенных кристаллов, не имеющих дефектов [25].

После воздействия ударной волны максимумы обеих полос смещаются в сторону высоких частот: для поперечных колебаний на $\sim 20 \mathrm{~cm}^{-1}$, а для продольных на $\sim 30 \mathrm{~cm}^{-1}$. Одновременно, полоса, соответствующая поперечным колебаниям кристаллической решетки $\mathrm{CaCO}_{3}$, становится несимметричной.

Смещение максимума полосы вызвано деформацией кристаллической решетки $\mathrm{CaCO}_{3}$. Величина смещения $\Delta v$ связана с эффективной величиной гидростатического давления $P$, вызывающего эту деформацию, выражением [26]

$$
\Delta v \approx \alpha P
$$

где $\Delta v=v_{P}-v_{0}, v_{P}$ и $v_{0}$ - частоты колебаний кристаллической решетки под давлением и без него, $\alpha=d v / d P$.

Для поперечных колебаний $\alpha=1.5 \mathrm{~cm}^{-1} / \mathrm{GPa}$ [26]. Тогда наблюдаемое смещение $-20 \mathrm{~cm}^{-1}$ максимума 


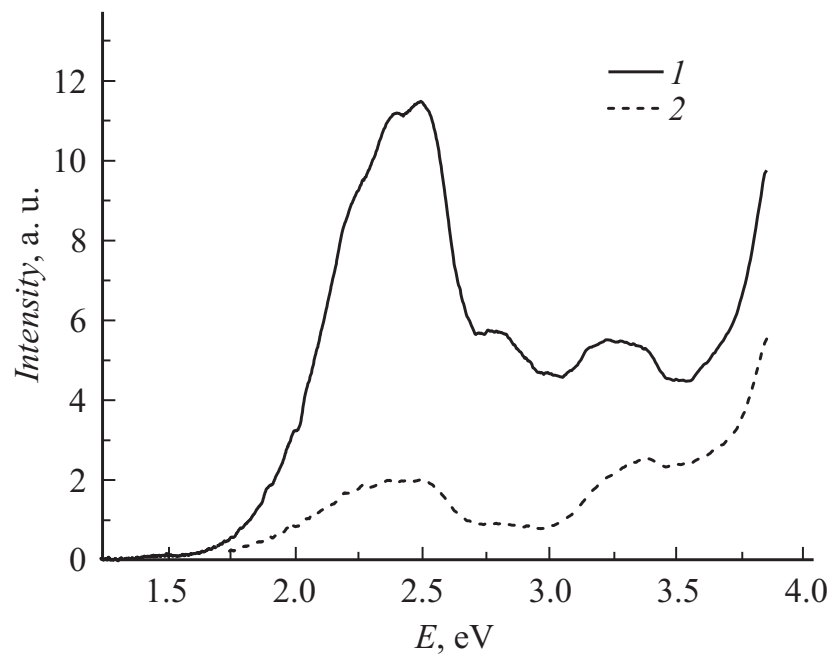

Рис. 6. Спектр ФЛ мрамора до (1) и после (2) воздействия ударной волны.

полосы, соответствующей таким колебаниям, может быть пересчитано в эффективное давление $P=20 / 1.5 \approx$ $\approx 13 \mathrm{GPa}$. При таком давлении $\mathrm{CaCO}_{3}$ I трансформируется в высокобарическую фазу $\mathrm{CaCO}_{3}$ III [12-14].

Как уже отмечалось, после воздействия ударной волны форма полосы, соответствующей поперечным колебаниям, становится несимметричной со стороны высоких частот. Этот эффект вызван тем, что деформация кристаллов $\mathrm{CaCO}_{3}$ III неоднородна. Наряду с кристаллами, сжатие которых соответствует эффективному давлению $13 \mathrm{GPa}$, есть кристаллы, в которых давление в несколько раз больше. Соответствующие таким кристаллам полосы смещаются больше и, налагаясь друг на друга, образуют высокочастотное крыло полосы.

\section{Данные ФЛ спектроскопии}

На рис. 6 представлены ФЛ спектры мрамора до и после воздействия ударной волны. В рассматриваемой области спектра от 1.7 до $2.6 \mathrm{eV}$ наблюдается ряд сильно наложенных друг на друга полос. Они приписаны излучению ионов $\mathrm{Mn}^{2+}, \mathrm{Sm}^{3+}, \mathrm{UO}_{2}^{2+}, \mathrm{Dy}^{3+}, \mathrm{Tb}^{3+}$, $\mathrm{Eu}^{3+}[27-32]$. Видно, что после воздействия ударной волны интенсивность всех полос в области $1-4 \mathrm{eV}$ уменьшилась в $\sim 4$ раза. Это показывает, что концентрация вышеупомянутых ионов в поверхностном слое, эффективная толщина которого $\sim 100 \mu \mathrm{m}$, также уменьшилась в $\sim 4$ раза.

\section{Заключение}

Анализ результатов исследования мрамора методами рамановской, ИК и ФЛ спектроскопии показал, что ударная волна в поверхностном слое образца толщиной

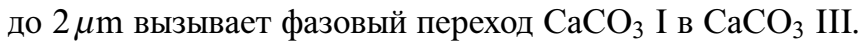

Одновременно в поверхностном слое в $\sim 4$ раза уменьшается концентрация примесных ионов $\mathrm{Mn}^{2+}, \mathrm{Sm}^{3+}$, $\mathrm{UO}_{2}^{2+}$ и др.

Работа выполнена при финансовой поддержке РФФИ, грант 16-05-00137.

\section{Список литературы}

[1] Фортов B.Е. // УФН. 2007. Т. 177. С. 348-368.

[2] Kanel G.I., Razorenov S.V., Fortov V.E. Shock-Wave Phenomena and the Properties of Condensed Matter. NY: Springer, 2004. $322 \mathrm{p}$.

[3] Малыгин Г.А., Огарков С.Л., Андрияш А.В. // ФТТ. 2015. T. 57. C. $1772-1779$.

[4] Мальгин Г.А. // ФТТ. 2015. Т. 57. С. 955-960.

[5] Веттегрень В.И., Щербаков И.П., Воронин А.В., Куксенко В.С., Мамалимов Р.И. // ФТТ. 2014. Т. 56. Вып. 2. C. 315-317.

[6] Веттегрень В.И., Щербаков И.П., Воронин А.В., Куксенко В.С., Мамалимов Р.И. // ФТТ. 2014. Т. 56. Вып. 5. C. $981-985$.

[7] Веттегрень В.И., Щербаков И.П., Куксенко В.С., Мамалимов Р.И. // ФТТ. 2014. Т. 56. Вып. 9. С. 1767-1771.

[8] Веттегрень В.И., Куксенко В.С., Щербаков И.П. // Физика Земли. 2016. № 5. С. 134-149.

[9] Щербаков И.П., Веттегрень В.И., Мамалимов Р.И. // ЖТФ. 2017. Т. 87. В печати.

[10] Веттегрень В.И., Куксенко В.С., Щербаков И.П., Мамалимов Р.И. // ФТТ. 2015. Т. 57. С. 2385-2387.

[11] Веттегрень В.И., Щербаков И.П., Мамалимов Р.И., Кулик В.Б. // ФТТ. 2016. Т. 58. С. 681-684.

[12] Merrill L., Bassett W.A. // Acta Crystallographica B. 1975. Vol. 31. P. 343-349.

[13] Merlini M., Crichton W.A., Chantel J., Guignard J., Poli S. // Mineralogical Magazine. 2014. Vol. 78 (2). P. 225-233.

[14] Catalli K., Williams Q. // American Mineralogist. 2005. Vol. 90. P. 1679-1682.

[15] Абрамова К.Б., Щербаков И.П., Русаков А.И. // ЖТФ. 1999. Т. 69. Вып. 2. Р. 137-140.

[16] Kuzmenko A.B. // Rev. Sci. Instr. 2005. Vol. 76. P. 083108.

[17] Born M., Wolf E. Principles of optics. Second Ed. Oxford: Pergamon press., 1964. $856 \mathrm{p}$.

[18] Gunasekaran S., Anbalagan G., Pandi S.J. // Raman Spectrosc. 2006. Vol. 37. P. 892-899.

[19] Huang E., Chen C.H., Huang T., Lin E.H., Xu J.-A. // Am. Mineralogist. 2000. Vol. 86. P. 473-479.

[20] Richet P., Mysen B.O., Ingrin J. // Phys. Chem. Minerals. 1998. Vol. 25. P. 401-414.

[21] Gunasekaran S., Anbalagan G., Pandi S. // J. Raman Spectrosc. 2006. Vol. 37. P. 892-899.

[22] Lou D., Sun F., Li L. // Chinese Opt. Lett. 2007. Vol. 5. N 6. P. $370-372$

[23] Noël L.V.Y., Orlando R., Zicovich-Wilson C.M., Ferrero M., Dovesi R. // Theor. Chem. Acc. 2007. Vol. 117. P. 991-1000.

[24] Catalli K., Williams Q. // American Mineralogist. 2005. Vol. 90. P. 1679-1682.

[25] Madelung $O$. Festkörpertheorie. Berlin: Springer Verlag. 1972. $418 \mathrm{p}$.

[26] Williams Q., Collerson B., Knittle E. // American Mineralogist. 1992. Vol. 77. P. 1158-1165. 
[27] Reeder J., Nugent M., Tait C.D., Morris D.E., Heald S.M., Beck K.M., Hess W.P., Lanzirotti A. // Geochim. Cosmochim. Acta. 2001. Vol. 65. P. 3491-3503.

[28] Polikreti K., Christofides C. // Appl. Phys. A. 2008. Vol. 90. P. 285-291.

[29] Habermann D., Neuser R., Richter D.K. // Sediment. Geol. 1998. Vol. 116. P. 13-24.

[30] Polikreti K., Christofides C. // Appl. Phys. A. 2008. Vol. 90. P. 285-291.

[31] Calderon T., Aguilar M., Jaque F., Coyll R. // J. Phys. C.: Solid State Phys. 1984. Vol. 17. P. 2027-2038.

[32] Reeder J., Nugent M., Tait C.D., Morris D.E., Heald S.M., Beck K.M., Hess W.P., Lanzirotti A. // Geochim. Cosmochim. Acta. 2001. Vol. 65. P. 3491-3503. 